\title{
Improving Child Nutritional Status in Order to Fill the Demographic Dividend in East Java Province, Indonesia
}

\author{
Lutfi Agus Salim ${ }^{1}$ \\ ${ }^{1}$ Department of Biostatistic and Demography, Faculty of Public Health, Universitas Airlangga, Surabaya, \\ Indonesia \\ Correspondence: Lutfi Agus Salim, Department of Biostatistic and Demography, Faculty of Public Health, \\ Universitas Airlangga, Surabaya, Indonesia. E-mail: lutfi.as@fkm.unair.ac.id
}

Received: April 3, $2020 \quad$ Accepted: April 23, $2020 \quad$ Online Published: April 30, 2020

doi:10.5539/ass.v16n5p120

URL: https://doi.org/10.5539/ass.v16n5p120

\begin{abstract}
All Indonesian children are national assets where the future of the nation depends on their quality. East Java Province experienced a demographic bonus period and the peak occurred in 2019 and a third of the population of East Java were children aged 0-17 years. Now the government of East Java Province has implemented five strategies in dealing with demographic bonuses, namely improving the quality of youth human resources, creating quality human resources, placing the elderly population as assets, improving health efforts, and economic empowerment. In the strategy of increasing health efforts, it is necessary to evaluate the nutritional status of children and toddlers. Improving the nutritional status of the community is one of the efforts that has a significant impact and is one of the determining factors for improving the quality of human resources. At the individual level, nutritional conditions are influenced by nutritional intake and related infectious diseases. The first two years of life is a critical period, if there are nutritional disorders in this period, the impact is permanent.
\end{abstract}

Keywords: children, golden age, demographic dividend

\section{Introduction}

All Indonesian children are national assets. Thus, the future of the nation depends on their quality. Once their existence is strategic, their main interests for growth and development must receive high priority in development (Council, 2004).

Population in East Java in 2019 reached 39,698,631 people and around 28.4 percent of them were children aged 0-17 years. This shows that investing for children is investing for one third of East Java's population (Central Bureau of Statistics, 2019a). Description of the child's current condition becomes an important basis for making appropriate policies for children. Children are a group of young people who have the potential to be developed so that they can actively participate in the development of East Java in the future (Central Bureau of Statistics, 2019b).

East Java Province experienced a demographic bonus period and the peak occurred in 2019. This demographic bonus is a result of its successful development of population and health is the decrease in the number of births, the number of deaths and increasing life expectancy of the population. The decline in the number of births and deaths in the long run will cause a change in the structure of the population, namely a decrease in the proportion of children and an increase in the proportion of productive age. On the other hand, increasing the life expectancy of the population and improving the quality of public health will impact on increasing the number of elderly residents. Changes in population structure will reduce the burden of dependency that must be borne by the population of productive age (Central Bureau of Statistics, 2019b).

In order to fill the demographic bonus, the program to improve child nutrition is a priority in the health sector in East Java Province. One of them is the handling of malnutrition, namely the occurrence of malnutrition problems not due to poverty, but rather caused by faulty parenting or intake. Because, on average, children included in the category of malnutrition in East Java are the children of able people, not poor people. Therefore, the handling of the problem of malnutrition in East Java must be done jointly between the government and social organizations such as the PKK through intensive preventive promotive socialization (Malik, 2015).

Handling of nutrition must be prepared since in the womb becomes important and should not be ignored. Mainly 
maintaining nutrition from the first 1,000 days of life (López-fernández, Barrios, Goberna-tricas, \& Gómez-benito, 2017). The basic service needs of children must be prepared by the government. Likewise, parental participation is still very much needed for access to health services in order to reduce morbidity and mortality in infants, toddlers, and children. Children, both infants and toddlers, need good health services, so they can get through the critical years early in life, considering their health is very vulnerable to various types of diseases. The East Java Provincial Government's efforts to improve children's health through immunization services, providing vitamins and supplementary food play an important role in reducing infant mortality and improving the quality of their health (WHO, 2013).

\section{Methods}

This study was part of a yearlong investigation in 2017-2018 that evaluated the child and maternal health program by East Java Governance. I analyzed the medium-term planning documents ( 5 years) by the East Java Provincial Government, and the annual health report by the Ministry of Health in East Java Province. to get data support I analyzed from several documents including, the health profile of the ministry of health in the province of East Java, the projected population of the Central Beurau of Statistic, the welfare indicators of the people of East Java Province from the Central Beurau of Statistic.

\section{Definition of Demographic Bonus and East Java Provincial Government Strategy in Overcoming It}

A country or region is said to have a demographic bonus if its dependency ratio is below 50.0 percent. The decline in the dependency ratio will one day reach the lowest point (which is usually below 50\%), called The Window of Opportunity where the opportunity is very short only occurs once in a decade of the entire life journey of the population (Allen \& Katz, 2010).

A demographic bonus is an opportunity for a country's economic prosperity because of the large proportion of the productive population (aged 15-64 years). If this opportunity is not utilized to its full potential, it will become an anti demographic (bomb disaster) demography (Cruz \& Ahmed, 2018). East Java Province is estimated to reach the peak of demographic bonus in 2019, namely at the productive age reaching 69.50 percent and Dependency Ratio of 43 (Central Bureau of Statistics, 2019a). The following are some strategies that can be carried out by the government in the form of improving the quality of human resources.

\subsection{Efforts to Improve the Quality of Youth}

To deal with demographic bonuses, various preparations need to be made, especially improving the quality of human resources, improving work skills. Improving the quality of human resources needs to be encouraged starting from the smallest community institutions, namely the family. The development of a prosperous family will provide educational platforms for future generations, especially adolescents who will soon enter the productive age. Encourage the creation of quality families so that it is expected to produce a quality generation, especially for adolescents in the family (Ishag, Mohamed, Mohammed, Nizam, \& Barom, 2020).

a. Restore the function of the family so that it can help the process of adolescent development that is full of dynamics

b. Provide a forum or event that provides opportunities for adolescents to appreciate their talents and abilities

c. Incorporating life skills learning into the school curriculum so that graduates can be ready to use

d. Maximizing the GenRe Program in schools, colleges and the surrounding environment through advocacy and IEC

e. Increase awareness and participation of government and stakeholders in making pro-youth policies

Youth human resource development is in line with population-oriented development policies that place the population at the center of development. The basic concept of development associated with population is a process of change towards better conditions or more advanced levels. Development must be able to create better conditions so that the quality of the population is better. Development policies for adolescents is how to increase the level of education and the development of life skills (Hanushek \& Woessmann, 2010).

Learning life skills is considered important for adolescents as potential successors in development because it can help teens achieve the task of personal growth and development both physically, mentally, emotionally and spiritually. Besides this learning can help teenagers enter the next life and then become productive HR. Teenagers as students and students who have life skills will be the capital of development as an HR that is reliable in IQ, EQ and SQ. they are the ones who will become the pioneers, potential drivers of future development (Hanushek \& Woessmann, 2010). 


\subsection{Creating Quality Human Resources}

Decreasing the number of children born gives the discretion to improve the quality of the family (Ashraf, Weil, $\&$ Wilde, 2011). All expenses can be focused more on education and health to improve the quality of competitive human resources. Improving the quality of the population of productive age can be done by providing skills that are in accordance with the needs of the labor market with competitive quality. Demographic bonus will only occur when there is a demographic engineering effort that is accompanied by an increase in the quality of human resources (Lee, Romich, Young, Hook, \& Marcenko, 2017).

Preparation and utilization of demographic bonuses one of which includes the expansion of universal secondary education and strengthening the linkages of vocational and industrial education and training. For this reason, a strategy is needed to improve the quality of education in Indonesia in an effort to create a demographic bonus as a window of opportunity. Education has a big role in developing human resources, namely developing people into productive power or manpower, which is why there is an educational approach known as the man power approach. In this approach education is emphasized on building development power. The development of education in relation to human resources which means the development of education is not only the provision of knowledge but is more emphasized on the ability of humans to carry out their work duties (Roy, Morton, \& Bhattacharya, 2018).

Education is believed to be one way to gain knowledge and skills. Improving the education program is not enough just to eradicate illiteracy for the people of Indonesia, but by continuing to increase school participation from the community. The Nine Year Compulsory Education Program that has been successfully promoted by the government must be increased to 12 years compulsory education and so on. Providing broad opportunities for people to get secondary and higher education, especially for low-income people by providing scholarships or cross subsidies.

The need for a revolution in the education curriculum which in each subject / lecture incorporates elements of entrepreneurship in students. This needs to be done starting from basic education to tertiary institutions without ignoring the character education that is currently running. At present this has not been done optimally, especially at the university level. As a result, the number of educated unemployed continues to grow because not all graduates can be accommodated in the world of work due to the lack of skills and entrepreneurial spirit possessed (Ashraf et al., 2011).

\subsection{Placing the Elderly as an Asset, Not a Burden}

Being in the era of demographic bonus and its continuation in the future, the increase in the elderly population in the future can be used as a potential rather than a burden. Older people with health problems and declining productivity can be a burden. But with the improvement in the quality of existing health, the elderly population is expected to continue to be able to produce (Roy et al., 2018).

To get a productive elderly population, population-based development programs are needed and the programs are long-term. The benefits of this development program are not immediately felt, for example with development that prioritizes increased resources. Development that focuses on improving the quality of human resources will have a positive impact on development in an area. This is because the large number of qualified population will be the capital of development and vice versa, the large number of residents can be a burden of a government if the quality of the population is low (Islam, 2020).

\subsection{Increased Health Efforts}

Development programs in the health sector that prepare a healthy population and are not easily sick so that those who later enter old age will still be healthy. With good health, they can still be productive in the country's economy. Not only preparing people who are not easy to get sick, but the state must also protect them with health insurance that is a safeguard for people when they are sick. In addition, from the community's point of view, there must be a continuing awareness program to save money or to participate in a pension fund program that can be relied upon when retirement has arrived (Islam, 2020).

Health efforts also have a role to play in improving the quality of human resources so they are able to take advantage of opportunities in demographic bonuses. The strategies in the health services sector are as follows:

a. Increasing access and quality of primary level health services

b. Increasing Access and Quality of Referral Health Services

c. Healthy Life Movement Community Program

d. Cross-sector involvement and all development sectors including the community in the implementation of 
health development

e. Family Approach. Health services by reaching out to all families in the work area of the community health center

\subsection{Economic Empowerment}

With the Demographic Bonus being The Window of Opportunity through birth prevented. This fact will significantly influence the increase in family opportunities for productive activities. Productive activities will lead to an increase in community welfare, namely: a) Increasing women's motivation to enter the labor market, b) Increasing the role of women, c) Community savings, and d) Human capital available. The Demographic Bonus will trigger the growth of savings, through this savings capital accumulation can be formed to invest in increasing economic growth which will contribute to improving people's welfare, in a greater sense. This economic growth is related to the population as a result of the age dependency model through a birth averted (Madjid, 2013).

\section{Condition of Toddlers Nutrition and Health Status in East Java}

Health is a state of physical, mental and complete social well-being, not just not having illness or weakness. Whereas a child is said to be healthy if he follows a pattern of development and growth that is appropriate to his age (Masia, Smerling, Kapfidze, Manning, \& Showalter, 2018). Some data about the nutritional and health conditions of children under five in East Java are presented in the following description.

\subsection{Complete Basic Immunization in Infants in East Java Province}

Complete basic immunization in infants if the baby has received hepatitis B immunization, one dose of BCG immunization, three doses of DPT-HB / DPT-HB-Hib immunization, four doses of polio immunization, and one dose of measles immunization.

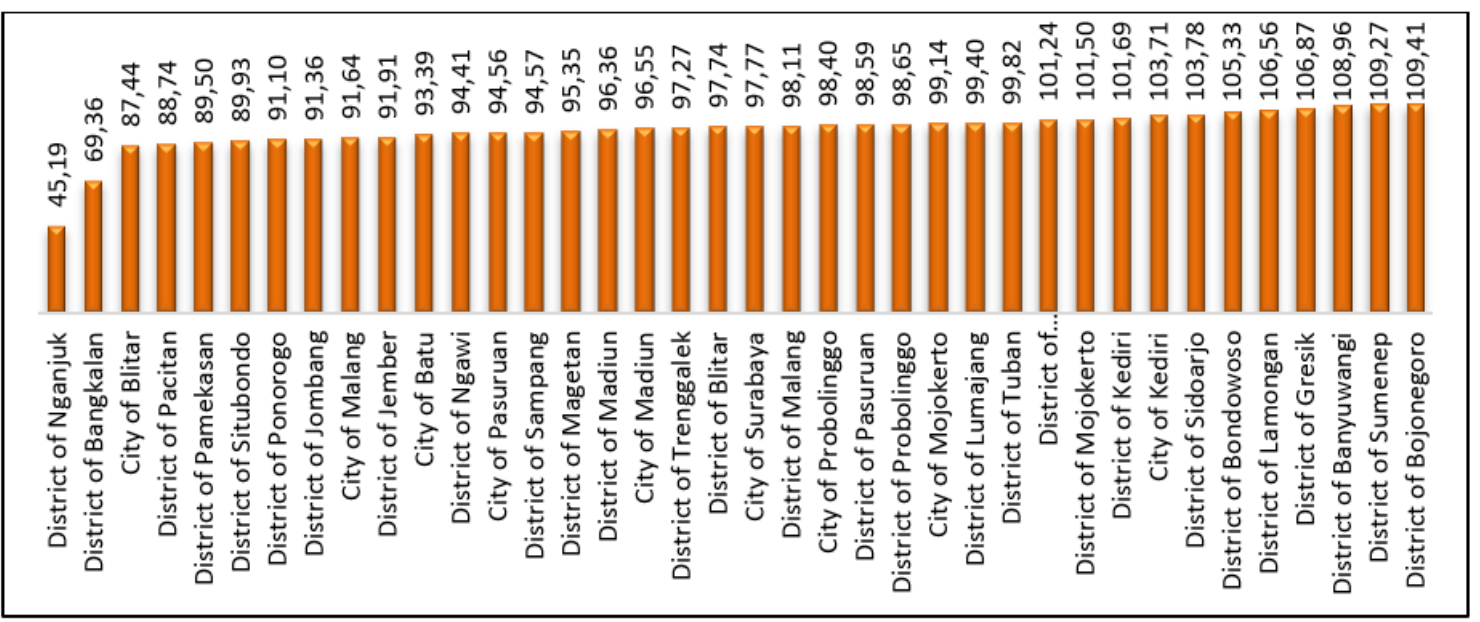

Figure 1. Complete basic immunization coverage per district / city of East Java Province in 2018 (Ministry of Health in East Java, 2019)

In 2018 the complete basic immunization coverage of East Java Province is 96.74\%. There are 11 regencies / cities with $100 \%$ or more coverage. Nganjuk Regency has the lowest coverage of $45.19 \%$ and Bojonegoro Regency has a weekly coverage of $109.41 \%$.

\subsection{Prevention and Management of Disorders Due to Iodine Deficiency}

The Problem of Iodine Deficiency Disorders (IDD) in East Java is still a nutritional problem that needs to be taken seriously considering its impact on the quality of human resources. Iodine deficiency can cause Goiter and Cretinism problems and result in decreased intelligence. Iodine Deficiency Disorders arise because the body lacks iodine continuously for a long time. The impact of iodine deficiency is not limited to mumps and creatinism, but it turns out that iodine deficiency affects the quality of human resources at large, including growth and development, including brain development so that there is a decrease in the potential level of intelligence (intelligence Quuotien). 


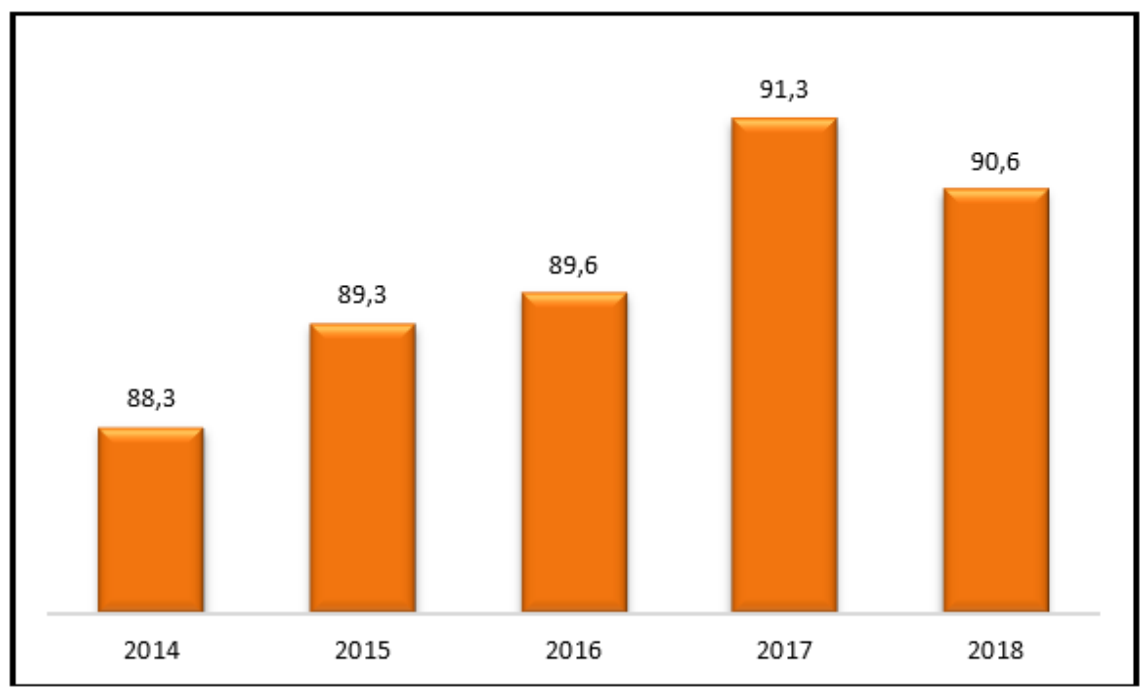

Figure 2. Development of Household Coverage Using Iodized Salt (Ministry of Health in East Java, 2019)

Efforts to overcome IDD in East Java are carried out through optimizing the use of iodized salt and counseling about iodized natural food ingredients. Based on the results of monitoring of iodized salt through the 2018 Monthly Nutrition Report, the percentage of households using iodized salt in East Java is $90.6 \%$. This figure is still above the East Java target of $90 \%$. The percentage of people who consume iodized salt has decreased when compared to 2017 by $91.3 \%$. Efforts to overcome IDD problems prioritize iodized salt promotion activities. For endemic areas of IDD problems, efforts are being made to ensure that salt consumed is iodized salt through the preparation of regional regulations governing marketing of iodized salt.

\subsection{Prevention and Management of Iron Nutrition Anemia}

Efforts to prevent and control Iron Malnutrition Anemia are carried out through giving Priority Blood Tablets to pregnant women, because the prevalence of anemia in this group is still quite high. In addition, the group of pregnant women is a vulnerable group that has the potential to contribute to the high maternal mortality rate (MMR).

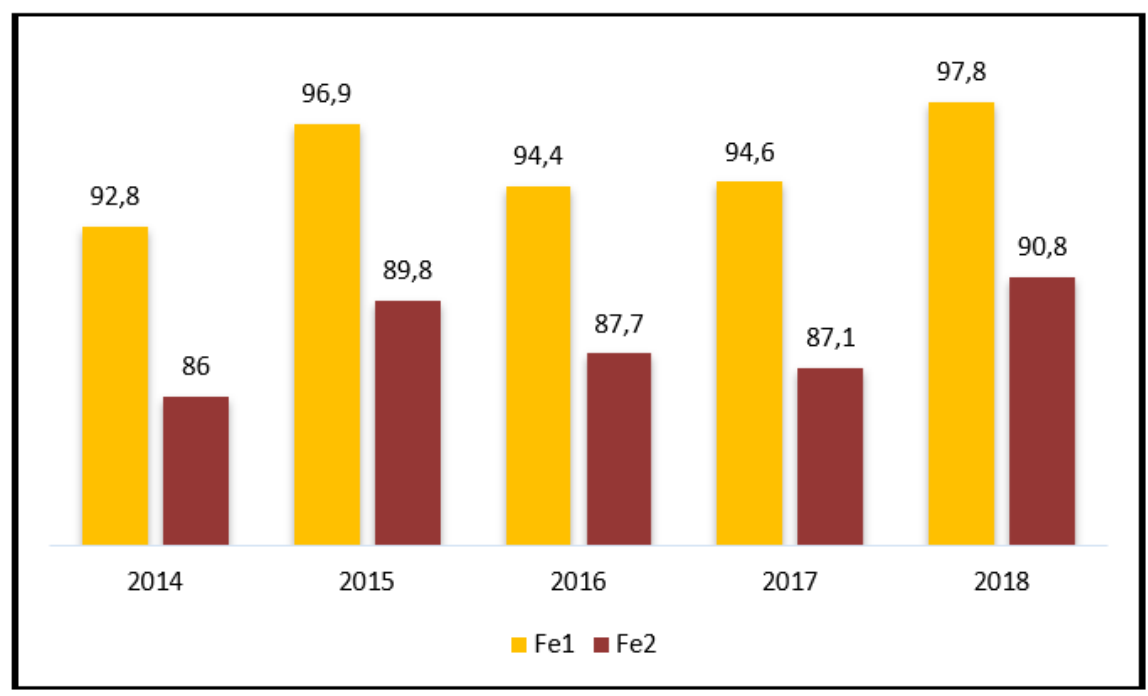

Figure 3. Development of Coverage of Fe1 and Fe3 in Pregnant Women (Ministry of Health in East Java, 2019)

To prevent Nutritional Anemia in pregnant women supplemented with Blood Tablet Supplementation with a daily dose of 1 tablet $(60 \mathrm{mg}$ Elemental Iron and $0.4 \mathrm{mg}$ Folic Acid) for at least 90 days during pregnancy. In 2017, the percentage of coverage of pregnant women in East Java who received Blood Tablets added as many as 30 tablets by $97.8 \%$ and those who received 90 tablets by $90.8 \%$

\subsection{Provision of Vitamin A Capsules in Toddlers}

Coverage of vitamin A capsules in East Java in 2018 for infants is 92.8\%. The coverage has met the 2018 target 
of $85 \%$. The strategy to overcome vitamin A deficiency is implemented comprehensively, consisting of supplementing high dose vitamin A capsules every February and August, counseling balanced nutrition to increase consumption of food sources of vitamin A and fortification of food. An overview of the coverage of vitamin A capsules in infants over the past 5 years can be seen in Figure 2 below.

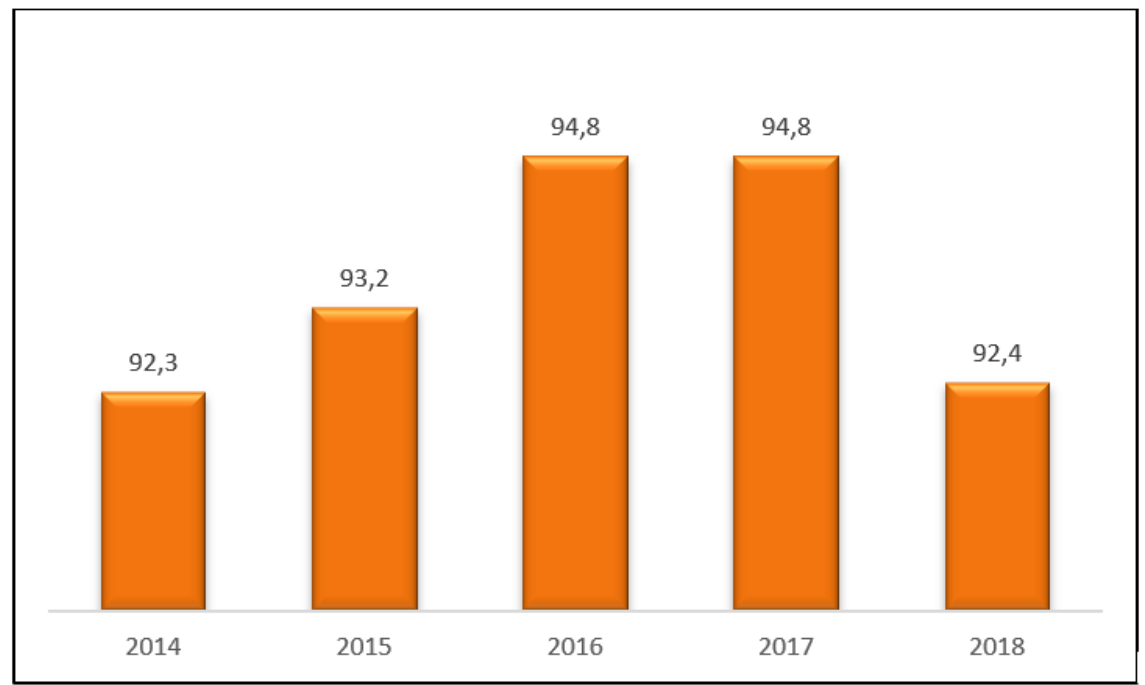

Figure 4. Development of the provision of vitamin A in infants in East Java province in 2014-2018 (Ministry of Health in East Java, 2019)

\subsection{Exclusive Breast Milk Coverage}

Exclusive breastfeeding is only breastfeeding without food and other drinks until the baby is 6 months old, then breastfeeding should continue until the baby is two years old even though the baby has been introduced to food.

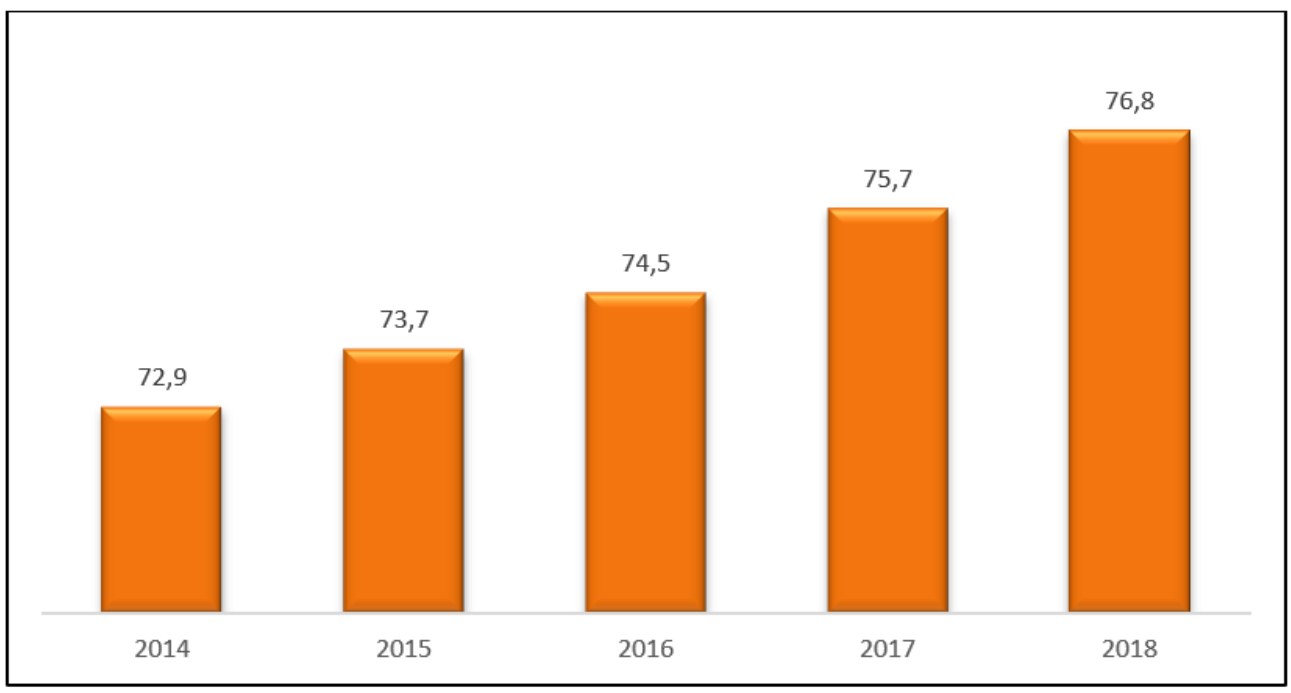

Figure 5. Development of exclusive breastfeeding coverage for infants 0-6 months of East Java province in 2014-2018 (Ministry of Health in East Java, 2019)

Based on data from districts / cities, it is known that the coverage of infants receiving exclusive breastfeeding in East Java in 2018 is $76.8 \%$. The coverage increased compared to 2017 which was $75.7 \%$. The increase shows the increasing understanding of baby mothers about the importance of Exclusive Breast Milk for babies. Definition of Exclusive Breast Milk according to the Ministry of Health of the Republic of Indonesia and the World Health Organization, is babies aged 0-6 months who are still given breast milk only when recorded. That is, if there are babies who are 0 months or 1 month old and so on up to 5 months are still given Mother's Milk only, then at that time he was recorded as an exclusive $0-6$ months baby, so the numbers are clearly much higher compared to the pure 6 exclusive month. Efforts to increase the scope of exclusive breastfeeding are carried out with a variety of strategies, ranging from drafting a regulatory framework, increasing the capacity of staff and promoting exclusive breastfeeding. Government regulations have also been enforced, in which there are already duties and 
responsibilities of the Government and regional governments in the development of the Breast Milk Program, including establishing national and regional policies, carrying out advocacy and outreach and conducting supervision related to the provision of Exclusive Breast Milk.

\section{Problems and Solutions for Improving Nutrition and Children in East Java}

5.1 Mitigation of Protein Energy Deficiency

Problems:

- $\quad$ Not all nutrition workers in community health center and nutrition staff at District / City Hospital have participated in training on the management of malnourished children.

- The Nutrition Care Team (Pediatricians, Nutritionists, and Nurses) in several district / city hospitals that have received training in the management of malnutrition children has no team decision letter and cannot function optimally due to limited funds for the management of malnutrition children.

Solutions:

Efforts to overcome the problem of controlling malnourished children under five have been carried out several activities, including:

- Immediately follow up on malnutrition cases by handling / treating these cases, so that no cases of malnourished children under five are neglected without treatment.

- Improving the ability of staff through Toddler Nutrition Management Training for Nutrition Care Teams in Hospitals and Health Care Centers.

- $\quad$ Providing assistance for general guidelines for the management of malnutrition toddlers.

- Providing Mineral Mix assistance as one of the ingredients for making WHO formula.

- Facilitating the establishment of Therapeutic Feeding Centers / Community Feeding Centers in several districts / cities.

- Strengthening the support of all stakeholders and cross-sectors / programs related to handling malnutrition through coordination meetings.

\subsection{Overcoming Disorders Due to Iodine Deficiency (IDD) Through the Utilization of Iodized Salt}

Problems:

- $\quad$ Not all officers have attended Iodized Salt Monitoring Training.

- There are still many iodized salts sold in the market that do not meet the standards.

- The socialization of iodized salt is not yet optimal in the community.

- Salt iodinization processes are still found in factories that do not meet the Indonesian National Standard requirements.

- $\quad$ There is a big difference in price between iodized and non-iodized salt

Solutions:

To overcome the problem of iodine deficiency, in order to prevent mumps and the emergence of new cases of cretin, the following efforts should be made:

- The need for strict rules and sanctions against producers who break the rules

- The need for intensive guidance for salt producers and farmers who have not yet done salt iodization.

- Increasing the socialization of the use of iodized salt to the public through various media, both print and electronic media

- Increasing iodized salt monitoring / monitoring activities in each village.

- Enhancing the formation of "Nutrition Conscious Families", one of which is the use of iodized salt in daily cooking.

\subsection{Tackling Iron Deficiency Anemia}

Problems:

- Not all Community health center in East Java have nutrition executive with a nutritional education background. 
- Tablets added to the blood provided by the program are less attractive, especially for pregnant women, so many do not want to consume them.

- $\quad$ Provision of IEC for counseling and outreach about anemia is still very limited

- Lack of cross-sectoral and cross-program roles in supporting anemia management programs.

- Campaigns and promotions about anemia in print and electronic media are still limited, so people lack understanding about the dangers of anemia.

Solutions:

To prevent and overcome Iron Nutrition Anemia in East Java, the following efforts should be made:

- Delivered a proposal for every health center throughout East Java to have a nutrition executive with a minimum Diploma-Nutrition education background.

- Increase monitoring activities on the use of blood-added tablets for pregnant women, together with the content of thezi

- $\quad$ Submit budget proposals both through national funds and provincial and district / city funds for campaign and promotion activities on anemia prevention

- Doing a movement to drink Iron tablets nationally in an effort to combat anemia through mass media, both print and electronic

- Iron tablets were replaced with coated tablets as many as 30 tablets per aluminum pack with the same composition to be preferred by pregnant women and women of childbearing age.

- Mutually beneficial, open and equal cooperation to improve the health status of women of childbearing age through partnerships (strengthening cross-program / cross-sector integration), mobilizing potential (mobilizing the community to create an environment to support the program), and empowering families that can foster independence.

- $\quad$ Fortification (adding iron to food)

\subsection{Overcoming Vitamin A Deficiency}

Problems:

- Availability of funds for overcoming Vitamin A deficiency and procurement of Vitamin A capsules is still less than optimal

- Support and participation of cross-program and cross-sectoral support for overcoming Vitamin A deficiency is still not optimal

- Sweeping activities to provide vitamin A capsules, are still not optimal so there are still toddlers who have not been able to get vitamin A capsules.

- Socialization activities and promotion of prevention and control of lack of vitamin A are still not optimal, especially in the use of food sources that contain a lot of vitamin A.

Solutions:

- To overcome the problem of vitamin A deficiency in society, the following efforts need to be made:

- Delivering budget proposals for the adequacy of vitamin A capsules in each district / city and sharing with provinces.

- Increase cooperation with cross-program and cross-sector, especially in increasing the coverage of vitamin A capsules.

- Conduct training / coaching for nutrition officers / managers in the District / City Health Service and Community health center regarding the management of vitamin A capsules.

- Further enhance sweeping activities, in an effort to maximize the coverage of vitamin A capsules.

- Increase counseling, especially in the use of food sources of vitamin A.

\subsection{Nutrition Awareness Family Campaign}

Problems:

- The application of "nutritionally aware family" in society is still relatively suboptimal

- $\quad$ Not all related agencies have contributed to increasing the range of "nutritionally aware families" in the 
community

- $\quad$ The lack of information provided to the public about the implementation of "nutritionally aware family".

- $\quad$ There are still limited facilities for IEC being prepared to support "nutritionally aware family" socialization activities.

- $\quad$ Most households that are not yet "nutritionally aware family", are caused by 2 factors, namely diverse food and exclusive breastfeeding.

Solutions:

- Increase training / coaching on "nutritionally aware family" for nutrition workers in community health center.

- Establish cooperation with cross programs and related sectors to contribute in developing "nutritionally aware family"

- $\quad$ Conduct monitoring / assessment of "nutritionally aware family" of households of at least 10 households in each posyandu.

- $\quad$ Increase the provision of IEC facilities to support the "nutritionally aware family" program

- $\quad$ Conduct a budget proposal to increase "nutritionally aware family" socialization.

\subsection{Exclusive Breastfeeding}

Problems:

- $\quad$ Not all nutrition implementers and midwives at the community health center have participated in training on Early Breastfeeding Initiation and Breast Milk Counselors in supporting exclusive breast milk.

- $\quad$ Not all health workers, both in Community Health Centers and Hospitals and other health service facilities, understand the Code of Conduct for Marketing Formula Milk.

- There is still a lack of understanding of all nutrition workers at the Community health center and District / City Health Offices regarding the operational definition of exclusive breastfeeding and its recording system, so there are still many babies who are separated from recording.

- $\quad$ Coverage of exclusive breastfeeding percentage in several districts / cities in East Java is very low so that it will affect the average provincial level coverage.

Solutions:

- Carry out Early Breastfeeding Initiation training and counselors and facilitators breastfeeding health workers in Community health center, Hospitals, and other health care facilities.

- $\quad$ Establish cooperation with cross-program, cross-sector, and related professional organizations to increase coverage of exclusive breastfeeding.

- Conduct supervision in the context of coaching to Community health center staff and other health service facilities about exclusive breastfeeding.

- $\quad$ Increasing the provision of IEC facilities to support increased exclusive breastfeeding coverage.

\section{Conclusions}

Improving the nutritional status of the community is one of the efforts that has a significant impact and is one of the determining factors for improving the quality of human resources. At the individual level, nutritional conditions are influenced by nutritional intake and related infectious diseases. If someone does not get enough nutrition will experience malnutrition and easily get sick. Likewise, if someone is often sick, it will cause an appetite disorder and subsequently will lead to malnutrition. While at the family and community level, nutritional problems are influenced by: knowledge, attitudes and skills of the family, the ability of the family to provide food for its members both in number and type according to nutritional needs, the availability of affordable and quality health and nutrition services, as well as the ability and knowledge of the family in personal and environmental hygiene matters.

Nutrition problems occur in every life cycle, starting from the fetus, baby, child, adult and old age. The period of the first two years of life is a critical period, because at this time there is very rapid growth and development. Nutritional disorders that occur in this period are permanent, meaning that they cannot be recovered even though the nutritional needs of the next period are met. 


\section{References}

Allen, H., \& Katz, R. (2010). Demography and Public Health Emergency Preparedness: Making the Connection. 527-539. https://doi.org/10.1007/s11113-009-9158-1

Ashraf, Q. H., Weil, D. N., \& Wilde, J. (2011). The effect of interventions to reduce fertility on economic growth. National Bureau of Economic Research.

Central Bureau of Statistics. (2019a). East Java in Municipality 2019.

Central Bureau of Statistics. (2019b). Welfare Statistic of Jawa Timur Province 2019.

Council, N. R. (2004). Children's health, the nation's wealth: Assessing and improving child health. National Academies Press.

Cruz, M., \& Ahmed, S. A. (2018). On the impact of demographic change on economic growth and poverty. World Development, 105, 95-106. https://doi.org/10.1016/j.worlddev.2017.12.018

Hanushek, E. A., \& Woessmann, L. (2010). Education and economic growth. Economics of Education, 60-67.

Ishag, A., Mohamed, A., Mohammed, M. O., Nizam, M., \& Barom, B. (2020). A Critical Analysis of Social Development: Features, Definitions, Dimensions and Frameworks. 16(1), 14-21. https://doi.org/10.5539/ass.v16n1p14

Islam, M. M. (2020). Demographic transition in Sultanate of Oman: emerging demographic dividend and challenges. 7. https://doi.org/10.1186/s43043-020-00022-7

Lee, J. S., Romich, J. L., Young, J., Hook, J. L., \& Marcenko, M. O. (2017). Children and Youth Services Review The impact of income on reuni fi cation among families with children in out-of-home care. Children and Youth Services Review, 72, 91-99. https://doi.org/10.1016/j.childyouth.2016.10.020

López-fernández, G., Barrios, M., Goberna-tricas, J., \& Gómez-benito, J. (2017). Breastfeeding during pregnancy: A systematic review. Women and Birth, 30(6), e292-e300. https://doi.org/10.1016/j.wombi.2017.05.008

Madjid, R. (2013). Kualitas Sumber Daya Manusia dalam Menggapai Bonus Demografi. Jurnal Transparansi, $6(1), 1$.

Malik, B. K. (2015). Youth development in India: Does poverty matter? SpringerPlus. https://doi.org/10.1186/s40064-015-1410-z

Masia, N. A., Smerling, J., Kapfidze, T., Manning, R., \& Showalter, M. (2018). Vaccination and GDP Growth Rates : Exploring the Links in a Conditional Convergence Framework. World Development, 103, 88-99. https://doi.org/10.1016/j.worlddev.2017.10.013

Ministry of Health in East Java. (2019). Health Profile in East Java 2018.

Roy, S., Morton, M., \& Bhattacharya, S. (2018). Hidden human capital: Self-efficacy, aspirations and achievements of adolescent and young women in India. World Development, 111, 161-180. https://doi.org/10.1016/j.worlddev.2018.07.002

WHO. (2013). Essential nutrition actions: Improving maternal, newborn, infant and young child health and nutrition. World Health Organization.

\section{Copyrights}

Copyright for this article is retained by the author(s), with first publication rights granted to the journal.

This is an open-access article distributed under the terms and conditions of the Creative Commons Attribution license (http://creativecommons.org/licenses/by/4.0/). 